\title{
Multi-storey structures with compound seismic isolation
}

\author{
M. C. Phocas \& G. Pamboris \\ Department of Civil and Environmental Engineering, \\ University of Cyprus, Cyprus
}

\begin{abstract}
Seismic isolation, one of the most innovative technologies in the area of performance-based design of buildings, has been increasingly used in the last 15 years worldwide. Seismic isolation is principally based on the incorporation of flexible isolators at the base of a building in order to shift its fundamental period outside the dangerous for the resonance range of periods. In extending the concept of base isolation, the present contribution refers to the control of multistorey structures under earthquake actions by means of introducing seismic isolation at different elevations of the structure. Thus, the structural response is influenced decisively by the vertically distributed seismic isolation, which at the respective storey-levels is alone capable of controlling the partial and overall stiffness, the force transmission and the energy dissipation process of the respective dynamic adaptable system. During moderate earthquakes the seismic isolated structure acts as an absorber of the kinetic energy at the isolation levels, thus minimizing the displacements of the building. During strong earthquakes the effectiveness of the system in further enlarging the period of the building, compared to the classical method of seismic isolation at a unique level, is achieved, most often with decreased inter-storey deflections, and without introducing extensive displacements at the building base, which are often limited by practical constraints. The effectiveness of the proposed control system is investigated in parametric studies, in the time-history range, for a six-storey building under ten earthquakes of the Greek-Mediterranean region. The most effective vertical distribution of seismic isolation at various storey-levels is proposed, based on a multi-criteria analysis of the responses of the isolated systems.
\end{abstract}

Keywords: structural control, seismic isolation, seismic performance. 


\section{Introduction}

Earthquake resistant structures that would develop an exclusive elastic behaviour under severe earthquake actions lead to prohibitive material consumption and construction costs. Almost all national and international earthquake resistance codes are based on adaptable structures that are able to absorb and dissipate a large amount of seismic energy through plastic deformations. This results in severe structural damage. In further improving the earthquake resistance of the structures within acceptable ranges, passive control may be achieved with the isolation of the building from the ground through isolation-damping devices. In this way the input earthquake energy of the structure is itself minimized, and the earthquake impacts are transmitted from the low tuned bearings to the building as smaller shear forces, through oscillations of lower frequency. Nevertheless, a limitation for the utilization of base isolation is the seismic gap or moat that must be provided around the structure to accommodate the large relative displacements at the isolation level. Another limitation factor is the possibility of poundings during strong earthquakes, which may result in local structural damage, excitation of higher modes and increased storey accelerations (Komodromos et al. [1]).

The present contribution refers to the control of multi-storey structures under earthquake actions by means of introducing seismic isolation at different elevations of the structure, as originally proposed by Phocas and Komodromos [2] and Earl and Ryan [3]. The isolation-damping devices introduced are herewith defined as controllable complex connections that provide, in a compact technique, different transmission characteristics in accordance with the loading conditions. Conceptually, it is assumed that the structural deformability is influenced decisively by the vertically distributed seismic isolation, which at the respective storey-levels is alone able to control the partial and overall stiffness, the force transmission and the energy dissipation process. In fact, a partitioned structure with such controllable connections can be looked at as a dynamic adaptable system, which represents in a whole two systems: a primary rigid one for transferring the normal horizontal and vertical loads and a secondary kinematical one, which is activated under dynamic actions.

Limited research activities have been undertaken up to date internationally on the distribution of seismic isolation over the height of the building. The concept of partial mass isolation is proposed for the seismic design of structures in the range of medium height to tall buildings, in Ziyaeifar and Noguchi [4]. Partial isolation is proposed to consist of a relatively flexible layer that consists of spring-damping components at a storey-level over the height of the building. The effectiveness of the method is demonstrated based on numerical investigations on a variety of structural types (medium height shear structures, tall shear structures and tall flexural structures).

The seismic response of isolated superstructures of base isolated buildings, subjected to deterministic earthquake input and random excitations, has been investigated, Pan et al. [5], and Pan and Cui [6]. A numerical analysis has been undertaken for a 16-storey frame structure, divided into four segments and 
interconnected by vibration isolation systems. Compared with a conventional base isolated building, the segmented building showed similar acceleration response in the superstructure, but significant reduction of the base displacement.

Roof level isolation of multi-storey buildings for the reduction of storey displacements has been proposed and investigated analytically and experimentally in Villaverde [7] and Villaverde et al. [8]. The detached building roof is hereby utilized as absorber mass, which is connected to the building body over isolation-damping mechanisms (elastomeric bearings with viscous or plastic hysteretic dampers). The results of the comparative study on a five storey steel structure indicate significant reduction of the earthquake response of the structure, even in the nonlinear region. The ground excitation in the analysis has been truncated in its first phase and scaled to match the natural frequency of the original structure.

Following a brief presentation of the control concept of vertically distributed seismic isolation in multi-storey buildings, the aim of the study is to investigate its effectiveness for ten actual earthquake motions of the Greek Mediterranean region. Several systems of a six-storey structure with seismic isolation at differing single or multiple elevations are compared to the original fixed supported structure, as regards the storey accelerations, -displacements, and shear forces. The properties of the seismic isolators for the parametric study are derived from actually developed isolation devices. The results of the parametric study are further evaluated, based on a multi-criteria analysis, whereas specific weight coefficients of the systems response parameters have been defined.

\section{Isolated structures}

Adaptable connections for multi-storey structures can be conceived to control the space motion of the three dimensional systems and the in-plane motion of symmetrical or planar structures. Practically, the in-space acting connections are bearings, which satisfy, in a compact technique, the requirements of rigidity, damping, elasticity and stability in such a manner, that in the absence of an earthquake they behave as three-dimensional bearings, able to transfer external actions according to strict deformation conditions, and are then able to change their characteristics when an earthquake occurs.

The adaptable earthquake isolators with progressive nonlinear deformability, documented in Pocanschi and Phocas [9], serve as passive adaptable multifunctional connections for the purposes of this study. Most promising feature of the isolator is its applicability with low vertical loads and its enhanced stability under dynamic actions, Phocas and Pocanschi [10].

For the numerical analysis a six-storey structure is considered, with possible seismic isolation at the base (SL0), at any upper storey or several storeys (SL1SL5). The isolation levels of the upper storeys are introduced underneath the respective storey masses, fig. 1 . Considering a six to six bay symmetrical structural system, the concentrated masses for each storey are set to $M_{s}=500$ $\mathrm{kNs}^{2} / \mathrm{m}$, a constant column stiffness of the MDF model was defined to $\mathrm{K}_{\mathrm{i}}=$ 
$1000 \mathrm{MN} / \mathrm{m}$ and the damping ratio to $\zeta_{\mathrm{s}}=0.02$. The properties of the developed seismic isolators account to a stiffness of $K_{i}=1202 \mathrm{kN} / \mathrm{m}$. The respective additional mass as to the introduction of isolation accounts to $\mathrm{M}_{\mathrm{i}}=$ $100 \mathrm{kNs}^{2} / \mathrm{m}$, i.e. $\mathrm{M}_{\mathrm{i}}=0.20 \mathrm{M}_{\mathrm{s}}$. This results from the mass of the devices and the mass of the required stiffening steel girders underneath. The stiffness of the isolator elements, introduced at a specific level refers to the number of isolators used, as to the resulting vertical load from the upper storeys, by taking into account a vertical loading of $700 \mathrm{kN}$ for each isolation device. The damping coefficient of the isolator level results from the number of isolators used, as to the damping coefficient of a single device of $0.58 \mathrm{kNs} / \mathrm{cm}$.

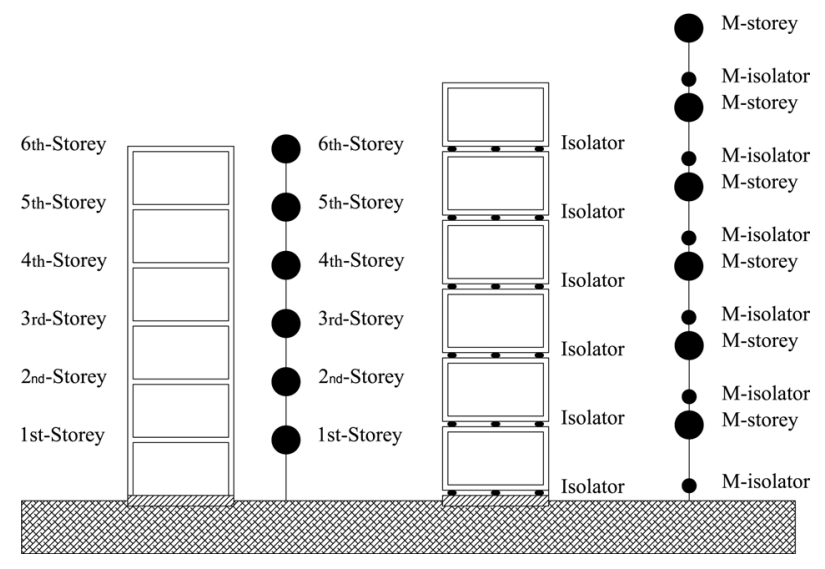

Figure 1: Isolators configurations for a six-storey building.

In terms of the dynamic behaviour, the structures with adaptable connections, i.e. seismic isolation at various storeys, are to be treated as non-stationary dynamic models, whose response can only be investigated by means of nonlinear dynamic analysis. The analysis assumes in general form the step-by-step integration of the system of 2 nd order differential equations:

$$
[\mathrm{M}]\{\ddot{\mathrm{x}}\}+[\mathrm{K}(\mathrm{x})]\{\mathrm{x}\}+\left[\mathrm{F}_{\mathrm{D}}\right]=-[\mathrm{M}]\left\{\ddot{\mathrm{U}}_{\mathrm{g}}\right\}
$$

where $[M]$ is the mass matrix, $\{\ddot{x}\}$ is the vector of accelerations, $\{x\}$ is the vector of displacements, $[\mathrm{K}(\mathrm{x})]$ is the lateral stiffness matrix of the system, $\left[F_{D}\right]$ is the vector of damping forces and $\left\{\ddot{U}_{g}\right\}$ is the vector of ground accelerations.

\section{Time-history analysis}

The MDOF-systems were used in the dynamic analysis in the time-history range (first $30 \mathrm{~s}$ ) for ten representative earthquake components of the Greek Mediterranean region, table 1 . The peak ground accelerations account to $0.10 \mathrm{~g}$ 
$\div 0.50 \mathrm{~g}$ and the large majority of the earthquake motions develop in their response spectra amplification values in the frequency area of $\omega=4$ to $81 / \mathrm{s}$, Ambraseys et al. [11].

Table 1: $\quad$ Earthquake components for the time-history analysis.

\begin{tabular}{|c|c|}
\hline Earthquake (record station, year. direction) & $\begin{array}{c}\text { Max. } \\
\text { Acceleration } \\
\ddot{\mathrm{U}}_{\mathrm{g}}[\mathrm{g}]\end{array}$ \\
\hline E1: Aigio 95 (Aigio, $0^{\circ}$ ) & 0.50 \\
\hline E2: Athens $99\left(\right.$ Sepolia, $\left.0^{\circ}\right)$ & 0.33 \\
\hline E3: Ionian 83 (Argostoli, 90) & 0.24 \\
\hline E4: Kalamata $86\left(\right.$ Kalamata, $\left.0^{\circ}\right)$ & 0.22 \\
\hline E5: Heraklio 84 (Heraklio, $\left.90^{\circ}\right)$ & 0.21 \\
\hline E6: Aigio 90 (Aigio, $\left.90^{\circ}\right)$ & 0.20 \\
\hline E7: Etolia 88 (Valsamata, $90^{\circ}$ ) & 0.18 \\
\hline E8: Killini 88 (Zakinthos, 90) & 0.15 \\
\hline E9: Preveza $81\left(\right.$ Preveza, $\left.0^{\circ}\right)$ & 0.14 \\
\hline E10: Gulf of Corinth 93 (Nafpaktos, $90^{\circ}$ ) & 0.10 \\
\hline
\end{tabular}

For the purposes of the parametric response study an algorithm has been developed with the programme Matlab, enabling the calculation of the earthquake induced total storey displacements $(U)$, inter-storey deflections (DU), absolute storey accelerations $\left(\mathrm{A}_{\mathrm{g}}\right)$ and storey shear forces $(\mathrm{F})$. The analysis has been conducted for the ten selected earthquake input motions and the possible combinations of the structure systems (system alternatives).

To facilitate the description in the numerical investigation, an index vector I is defined to indicate the positions of isolators within the building under consideration. The terms of vector I take values as follows:

$$
I_{\mathrm{i}}=\left\{\begin{array}{l}
0 \Rightarrow \text { isolation at level } \mathrm{i} \text { inactive } \\
1 \Rightarrow \text { isolation at level } \mathrm{i} \text { active }
\end{array}\right.
$$

For every system alternative the algorithm selects the maximum respective response for three different analysis cases: In the first case, the maximum values of the four response parameters ( $\left.\mathrm{U}, \mathrm{DU}, \mathrm{A}_{\mathrm{g}}, \mathrm{F}\right)$ are registered, that correspond to the maximum inter-storey deflection of every system alternative under any of the ten earthquake motions, fig. 2 ; in the second case, to the maximum absolute acceleration, fig. 3 ; in the third case, to the maximum shear forces, fig. 4 .

With a single isolation level over the height of the building, minimum relative deformations of the isolators are favoured by the base isolated alternative, 100000 , followed by the alternatives analogically to the sequence of storeys over the height, fig. 2. As regards the maximum accelerations of the single isolated alternatives, most effective is the system alternative 010000, fig. 3. The maximum reduction of the base shear force takes place, when the isolation level is at mid-height. Further reduction is observed, when the isolation level is placed at the fourth storey, fig. 4 . 



Figure 2: Analysis case 1, seismic responses of six-storey structures corresponding to a maximum inter-storey deflection of the systems.

By having two isolation levels over the height all maximum response parameters are further reduced compared to the single case (110000 for DU, 101000 for $\mathrm{A}_{\mathrm{g}}$ and 001010 for $\mathrm{F}$ ), while the total displacements remain in the same range. The same applies to the case of having three isolation levels (111000 for DU , 101100 for $\mathrm{A}_{\mathrm{g}}$ and 001011 for $\mathrm{F}$ ). 

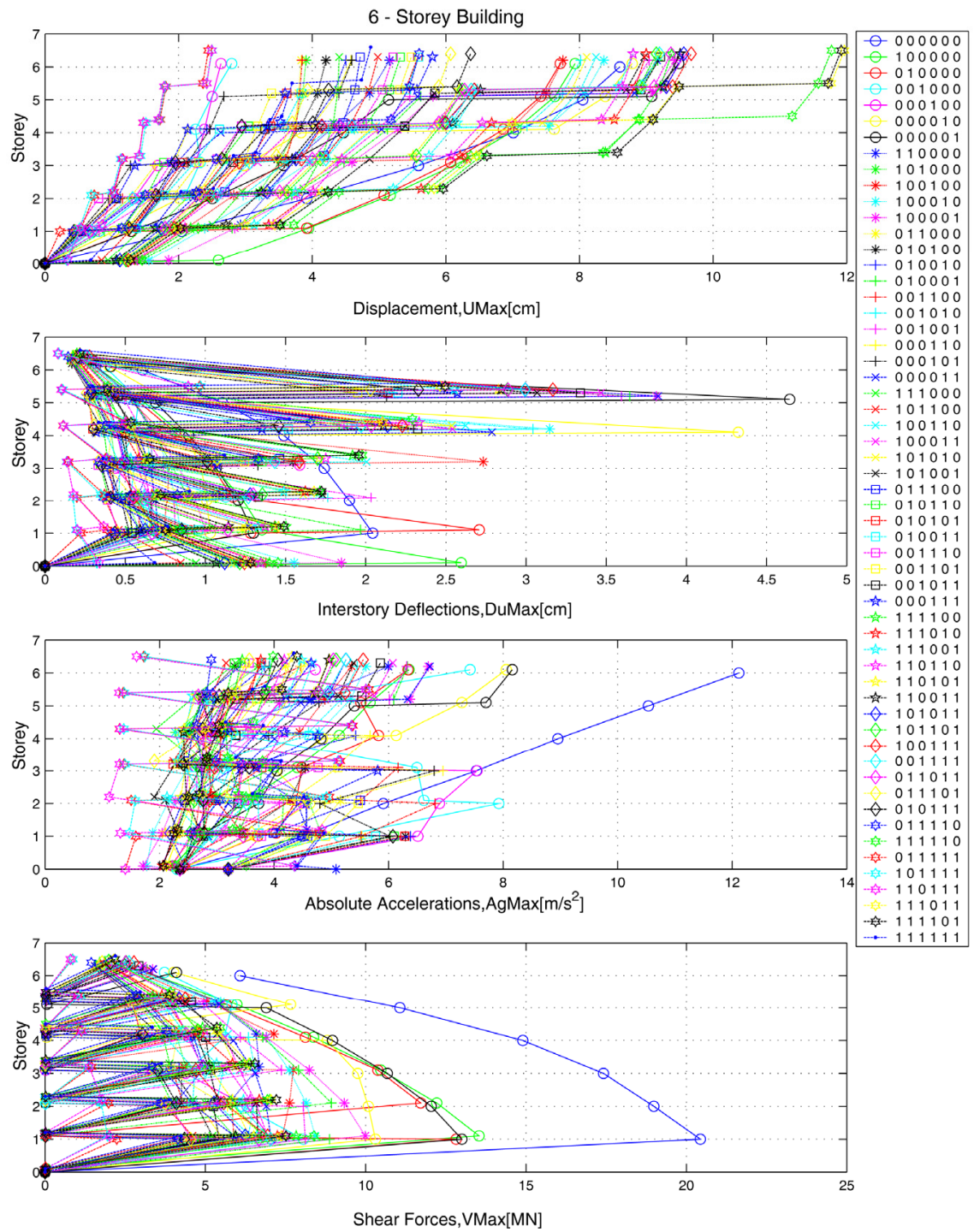

Figure 3: Analysis case 2, seismic responses of six-storey structures corresponding to a maximum absolute acceleration of the systems.

Structures having more than three isolation levels develop insignificant further reductions of their maximum responses compared to the three isolation levels alternative. In particular the lowest relative deformations of the isolators and the lowest absolute accelerations develop when the isolation levels are placed at the lower storeys. An optimized response as regards the base shear develops, when the systems have most high stiffness values at mid-height (110011 and 111011). 

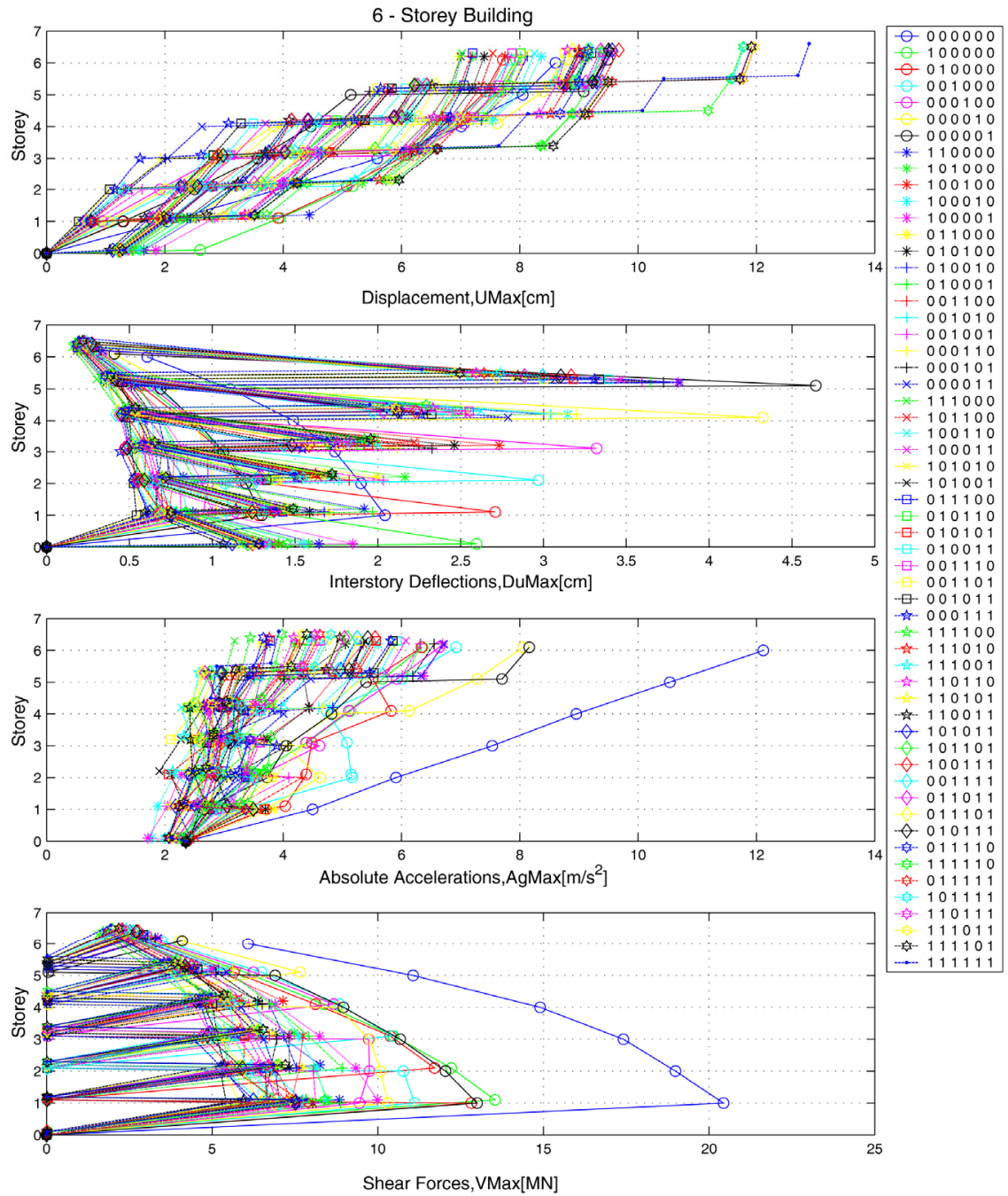

111111

Figure 4: Analysis case 3, seismic responses of six-storey structures corresponding to a maximum shear force of the systems.

\section{Multi-criteria analysis}

A multi-criteria analysis of the numerical results obtained from the parametric response-study of the analysis cases has been conducted with the software programme Dlab, for all values of the response parameters of the systems ( $\left.U, D U, A_{g}, F\right)$. A multitude of independent results exists for the specific problem evaluation, whose classification as to each analysis case and response parameter may depend on specific weight coefficients of all criteria applied in 
the analysis. The weight coefficients have been set, based on a preliminary estimation made by the authors as regards the significance of each criterion; e.g. the shear force in respect to the design of the structural members, the storey accelerations in respect to the safety of the storey equipment, the inter-storey deflections in respect to the maximum bearable relative deformation values of the isolation devices, and the total displacements in respect to the possibility of poundings with adjacent buildings.

The weight coefficient for the first analysis case $\left(\mathrm{DU}_{\max }\right)$ is set to $8 \%$, for the second analysis case $\left(\mathrm{A}_{\mathrm{g}, \max }\right)$, to $28 \%$, and for the third analysis case $\left(\mathrm{F}_{\max }\right)$, to $64 \%$. The weight coefficients of the response parameters account to $6 \%$ for $U$, $12 \%$ for DU , $26 \%$ for $\mathrm{A}_{\mathrm{g}}$ and $56 \%$ for $\mathrm{F}$. Based on the calculation method PROMETHEE II of the programme, that takes into consideration the above, an indicative classification of the structural systems seismic performance is provided in table 2.

Table 2: Classification results of the structural systems seismic performance as derived from the multi-criteria analysis.

\begin{tabular}{|c|c|c|c|c|c|c|c|}
\hline $\mathrm{A} / \mathrm{A}$ & Index & $\mathrm{A} / \mathrm{A}$ & Index & $\mathrm{A} / \mathrm{A}$ & Index & $\mathrm{A} / \mathrm{A}$ & Index \\
\hline 1 & 1010010 & 16 & 001011 & 31 & 111100 & 46 & 000011 \\
\hline 2 & 1111000 & 17 & 010101 & 32 & 101111 & 47 & 100010 \\
\hline 3 & 001101 & 18 & 001100 & 33 & 111101 & 48 & 001001 \\
\hline 4 & 100110 & 19 & 111111 & 34 & 011111 & 49 & 000100 \\
\hline 5 & 1110011 & 20 & 011011 & 35 & 001111 & 50 & 010000 \\
\hline 6 & 0111110 & 21 & 110111 & 36 & 110000 & 51 & 001000 \\
\hline 7 & 111001 & 22 & 010011 & 37 & 010100 & 52 & 010001 \\
\hline 8 & 0111101 & 23 & 001010 & 38 & 000101 & 53 & 1000000 \\
\hline 9 & 011100 & 24 & 101101 & 39 & 010111 & 54 & 000000 \\
\hline 10 & 010110 & 25 & 000111 & 40 & 100111 & 55 & 100001 \\
\hline 11 & 0011110 & 26 & 101001 & 41 & 010010 & 56 & 0000010 \\
\hline 12 & 111010 & 27 & 110110 & 42 & 000110 & 57 & 000001 \\
\hline 13 & 101100 & 28 & 011000 & 43 & 100011 & & \\
\hline 14 & 101011 & 29 & 111011 & 44 & 111110 & & \\
\hline 15 & 110101 & 30 & 101000 & 45 & 100100 & & \\
\hline
\end{tabular}

\section{Conclusions}

The intention of this paper is to extend the approach of base isolation and to investigate the potential effectiveness of multi-storey structures with seismic isolators at different storey-levels. The control concept aims at achieving structures with controlled deformability over the height. In the parametric study conducted the dynamic behaviour of the seismic isolated structures has proven to be substantially improved over the fixed supported structure, as regards the interstorey deflections, the absolute storey accelerations and the base shear force under earthquake actions. Main improvements in the seismic response of the 
isolated six-storey structures have been observed with three isolation levels over the height.

In order to obtain a thorough insight in the characteristics of the dynamic response of the isolated systems, a classification of the earthquake motions and further design variables for the primary structures and the seismic isolators are to be determined and evaluated in parametric studies.

\section{References}

[1] Komodromos, P., Polycarpou, P., Papaloizou, L. \& Phocas, M.C., Response of Seismically Isolated Buildings Considering Poundings. Earthquake Engineering and Structural Dynamics, 36, 1605-1622, 2007.

[2] Phocas, M.C. \& Komodromos, P. Multi-Storey Structures with Vertically Distributed Seismic Isolation. Koller, M., Giardini, D., (ed.), First European Conference on Earthquake Engineering, Geneva, Switzerland, Proceedings: Geneva, 2006.

[3] Earl, C.L. \& Ryan, K.L., Effectiveness and Feasibility of Inter-Storey Isolation Systems. Eighth U.S. National Conference on Earthquake Engineering. Managing Risk in Earthquake Country: San Francisco, California, 2006.

[4] Ziyaeifar, M. \& Noguchi, H., Partial Mass Isolation in Tall Buildings. Earthquake Engineering and Structural Dynamics, 27, 49-65, 1998.

[5] Pan, T.-C., Ling, S.-F. \& Cui, W., Seismic Response of Segmental Buildings. Earthquake Engineering and Structural Dynamics, 24, 10391048, 1995.

[6] Pan, T.-C. \& Cui, W., Response of Segmental Buildings to Random Seismic Motions. Earthquake Technology, 35/4, 105-112, 1998.

[7] Villaverde, R., Roof Isolation System to Reduce the Seismic Response of Buildings: A Preliminary Assessment. Earthquake Spectra, 14/3, 521-532, 1998.

[8] Villaverde, R., Aguirre, M. \& Hamilton, C., Aseismic Roof Isolation System Built with Steel Oval Elements: Exploratory Study. Earthquake Spectra, 21/1, 225-241, 2005.

[9] Pocanschi, A. \& Phocas, M.C., Adaptable Earthquake Isolator with Progressive Nonlinear Deformability. Engineering Structures, Elsevier Science, 29/10, 2586-2592, 2007

[10] Phocas, M.C. \& Pocanschi, A., Dynamic Adaptable Bearings. Development and Analysis. Eighth U.S. National Conference on Earthquake Engineering. Managing Risk in Earthquake Country: San Francisco, California, 2006.

[11] Ambraseys, N., Smit, P., Berardi, R., Rinaldis, D., Cotton, F. \& BergeThierry, C., Dissemination of European Strong-Motion Data. CD-ROM Collection, European Council, Environment and Climate Research Programme: Brussels, 2000. 